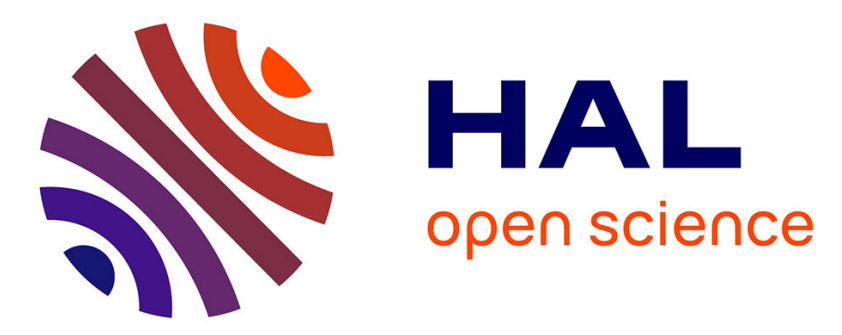

\title{
Les oïdiums des cucurbitacées. II. Mise au point d'une technique de conservation des souches en culture axénique
}

\author{
Paul-Michel Molot, Jean-Paul Leroux, Halina Ferrière
}

\section{- To cite this version:}

Paul-Michel Molot, Jean-Paul Leroux, Halina Ferrière. Les oïdiums des cucurbitacées. II. Mise au point d'une technique de conservation des souches en culture axénique. Agronomie, 1987, 7 (5), pp.339-343. 10.1051/agro:19870506 . hal-02728994

\section{HAL Id: hal-02728994 \\ https://hal.inrae.fr/hal-02728994}

Submitted on 2 Jun 2020

HAL is a multi-disciplinary open access archive for the deposit and dissemination of scientific research documents, whether they are published or not. The documents may come from teaching and research institutions in France or abroad, or from public or private research centers.
L'archive ouverte pluridisciplinaire HAL, est destinée au dépôt et à la diffusion de documents scientifiques de niveau recherche, publiés ou non, émanant des établissements d'enseignement et de recherche français ou étrangers, des laboratoires publics ou privés. 


\section{Les oïdiums des cucurbitacées. II. Mise au point d'une technique de conservation des sou- ches en culture axénique}

Paul-Michel MOLOT, Jean-Paul LEROUX \& Halina FERRIERE

I.N.R.A., Station de Pathologie végétale, Centre de Recherches d'Avignon, F 84140 Montfavet

RÉSUMÉ

Il est possible de maintenir, en conditions axéniques, sur feuilles adultes, différents oïdiums :

- Sphaerotheca fuliginea sur courgette ou concombre ;

- Erysiphe cichoracearum sur courgette ou concombre et sur tabac ;

- Leveillula taurica sur piment.

Les feuilles sont désinfectées par trempage pendant 3 minutes dans $\mathrm{HgCl}_{2}$ à 0,5 p. 1000 . Repiquées par leur pétiole sur milieu gélosé spécial, elles sont aussitôt après pulvérisées par une suspension de spores d'oïdium, elle-même désinfectée selon une technique originale par $\mathrm{HgCl}_{2}$ pendant moins de 2 minutes.

La formation de cals et même de racines (cas de la courgette et du concombre) assure à la feuille une survie d'environ 2 mois ( 4 mois si elle n'est pas contaminée par l'oïdium).

Après isolement d'une souche donnée, son repiquage "in vitro », à l'aide d'un pinceau, d'une feuille infectée à une feuille saine ne pose aucune difficulté.

Cette technique est comparée aux diverses méthodes utilisées pour la conservation des parasites obligatoires.

Mots clés additionnels : Sphaerotheca fuliginea, Erysiphe cichoracearum, Leveillula taurica, formation de cals, rhizogenèse, culture de tissus, courgette, concombre, tabac, piment, $\mathrm{HgCl}_{2}$, technique de désinfection.

Powdery mildews of cucurbits. II. A method for preserving isolates in axenic culture.

The following powdery mildews were preserved actively on detached adult leaves of different plants in a culture medium, in axenic conditions : Sphaerotheca fuliginea on squash or cucumber ; Erysiphe cichoracearum on squash, cucumber or tobacco ; Leveillula taurica on pepper. Detached leaves were first disinfected by soaking for 3 minutes in an aqueous solution of $0.05 \% \mathrm{HgCl}_{2}$, and their petioles planted into an agar medium (tissue culture). Leaves were then sprayed with spores of different powdery mildews, disinfected by an original technique involving $\mathrm{HgCl}_{2}$ for less than $2 \mathrm{~min}$. Spores were readily transferred from diseased to healthy leaves with a soft paint brush in axenic conditions. Callus and root formation (with cucumber and squash) allowed the leaves to survive as long as 2 months, or 4 months if not infected with powdery mildews. This technique is compared with other methods of conservation already in use for obligate parasites.

Additional key words : Sphaerotheca fuliginea, Erysiphe cichoracearum, Leveillula taurica, callus formation, rhizogenesis, tissue culture, squash, cucumber, tobacco, pepper, $\mathrm{HgCl}_{2}$, disinfection method.

\section{INTRODUCTION}

Ne se cultivant pas sur milieu nutritif gélosé, les parasites obligatoires sont classiquement conservés sur du matériel végétal vivant. Cette technique présente malheureusement de nombreux inconvénients, en particulier l'obligation de maintenir un cloisonnement rigoureux entre plantes hébergeant différents genres ou espèces d'oïdium. Pour remédier à cette situation, nous avons conçu et réalisé un système d'enceintes pressurisées permettant à la fois d'élever des plantes à l'abri de toute contamination et de conserver, après contamination, les souches d'oïdium sans risque de mélange (FAUVEL \& MOLOT, 1985).

Des techniques plus simples, visant à s'affranchir de la plante vivante, ont été proposées notamment la conservation des spores par le froid (DAHMEN et al., 1983 ; KonIDARIS, 1985). Elles sont utilisées, avec plus ou moins de succès, pour les rouilles et certains mildious. En ce qui concerne les oïdiums, nous ne disposons que de données rares et peu fiables. Des travaux personnels ont montré que l'on peut garder Sphaerotheca fuliginea au congélateur à $-18^{\circ} \mathrm{C}$ sous forme de spores sèches ou maintenues dans un liquide 
cryoprotecteur (10 p. 100 glycerol $+8,5$ p. 100 lait écrémé), mais la vitalité du matériel, assez faible dès le départ, diminue progressivement pour disparaître en totalité au bout de 5 à 6 mois ; de plus, ces méthodes ne semblent pas applicables à tous les oïdiums, en particulier à certaines souches d'Erysiphe cichoracearum.

Depuis 1951, date à laquelle la culture artificielle in vitro de Gymnosporangium juniperi-virginianae a pu être réalisée (HOTSON \& CUTTER, 1951), de nombreux parasites obligatoires dont Puccinia graminis f. sp. tritici (WILlaAms et al., 1966 et 1967 ; GRAMBOW \& RIEDEL, 1977 ; KUCK, 1979 ; KUCK \& REISENER, 1985) et Melampsora lini (BOSE \& SHAw, 1974) peuvent désormais donner lieu sur milieu gélosé à un développement mycélien accompagné ou non de sporulation.

Les articles de synthèse résumant l'ensemble de ces travaux (MACLEAN, 1982; WILLIAMS, 1984) ne font mention que des rouilles : la culture des oïdiums pose des problèmes encore non résolus.

Pour réaliser la conservation des parasites obligatoires, une solution élégante de laboratoire a été proposée avec la culture associée du champignon et des tissus végétaux (MOREL, 1948). Ces techniques nécessitant une bonne maîtrise des cultures de tissus ne sont cependant pas toujours d'une réalisation facile.

De façon beaucoup plus simple, il est possible d'obtenir la culture des parasites obligatoires sur feuilles détachées en boîte de Petri. La conservation peut s'effectuer soit en conditions non aseptiques, les feuilles "flottant " sur une solution de benzimidazole à 0,02-0,04 p. 100 (SAMBORSKI et al., 1958 ; DOLING, 1966), de kinétine à 0,01-0,02 p. 100 (WOLFE \& MACER, 1966), voire sur de l'eau (MOLOT \& LECOQ, 1986), soit en conditions aseptiques ; dans ce dernier cas, on fait généralement appel à des cotylédons (TuREL \& LeDingham, 1957) ou à de très jeunes organes foliaires déjà malades, par exemple des feuilles de blé âgées de 6 jours (WILLIAMS et al., 1966) que l'on dépose, après désinfection, sur un milieu approprié. Toutefois, ces méthodes de survie présentent deux inconvénients majeurs :

- elles concernent toujours des organes jeunes, présentant vis-à-vis de l'oïdium un comportement très variable ;

- la durée de conservation excède rarement une dizaine de jours (RAPILLY, 1968).

En nous inspirant de ces vitro méthodes, nous nous proposons de travailler sur feuilles adultes, de vérifier si elles sont capables de s'enraciner in vitro et donc de se conserver plus longtemps. Dans ces conditions, le matériel végétal doit-il être contaminé au préalable ou bien prélevé sain, puis infecté avec des spores d'oïdium non polluées par d'autres champignons?

\section{MATÉRIEL ET MÉTHODES}

\section{A. Matériel végétal et cryptogamique}

Pour mettre au point notre méthode de culture, nous avons utilisé des feuilles adultes prélevées sur différentes plantes : courgette var. Diamant, concom- bre var. Marketer, piment var. Yolo Wonder, tabac Nicotiana tabacum var. Xanthi n.c.

Les deux Cucurbitacées ont été contaminées avec une souche de $S$. fuliginea et une souche d'E. cichoracearum, toutes deux entretenues sur melon «Védrantais », le piment avec une souche de $L$. taurica entretenue sur piment "Yolo Wonder" et le tabac avec une souche d'E. cichoracearum provenant de cette même plante. Signalons que la souche de $L$. taurica utilisée est capable d'infecter le concombre et le melon (M. DIOP BRUCKLLER, comm. pers.).

\section{B. Composition du milieu nutritif gélosé nécessaire à l'enracinement de la feuille détachée}

Ce milieu ajusté avant autoclavage à pH 6 comprend les macro- et micro-éléments de MURASHIGE \& SKOOG, les vitamines de MOREL, ainsi que 3 substances de croissance. Il est faiblement gélosé $(8 \mathrm{~g} / \mathrm{l})$ et renferme, d'après les travaux de Valıos (1984), $30 \mathrm{~g}$ de saccharose.

$\begin{array}{ll}\text { Macro-éléments de MURASHIGE \& SKOOG }(\mathrm{mg} / \mathrm{l}) \\ \mathrm{NO}_{3} \mathrm{NH}_{4} & 1650 \\ \mathrm{KNO}_{3} & 1900 \\ \mathrm{CaCl}_{2}, 6 \mathrm{H}_{2} \mathrm{O} & 440 \\ \mathrm{MgSO}_{4}, 7 \mathrm{H}_{2} \mathrm{O} & 370 \\ \mathrm{PO}_{4} \mathrm{KH}_{2} & 170 \\ \mathrm{Na}_{2} \mathrm{EDTA} & 37,3 \\ \mathrm{FeSO}_{4}, 7 \mathrm{H}_{2} \mathrm{O} & 27,8\end{array}$

Micro-éléments de MURASHIGE et SKOOG $(\mathrm{mg} / \mathrm{l})$

$\begin{array}{ll}\mathrm{H}_{3} \mathrm{BO}_{3} & 6,2 \\ \mathrm{ZnSO}_{4}, 4 \mathrm{H}_{2} \mathrm{O} & 8,6 \\ \mathrm{MnSO}_{4}, 4 \mathrm{H}_{2} \mathrm{O} & 22,3 \\ \mathrm{IK} & 0,83 \\ \mathrm{CuSO}_{4}, 5 \mathrm{H}_{2} \mathrm{O} & 0,025 \\ \mathrm{CoCl}_{2}, 6 \mathrm{H}_{2} \mathrm{O} & 0,025 \\ \mathrm{Na}_{2} \mathrm{MoO}_{4}, 2 \mathrm{H}_{2} \mathrm{O} & 0,25\end{array}$

Vitamines de MOREL $(\mathrm{mg} / \mathrm{l})$

Calcium pantothenate 1

$\begin{array}{ll}\text { Inositol } & 100 \\ \text { Biotine } & 0,01 \\ \text { Acide nicotinique } & 1 \\ \text { Pyridoxine } \mathrm{HCl} & 1 \\ \text { Thiamine } \mathrm{HCl} & 1\end{array}$

Substances de croissance $(\mathrm{mg} / \mathrm{l})$

Acide indolbutyrique $\quad 1,5$

Acide 2,4 dichlorophenoxyacétique $\quad 1,0$

Kinétine

0,1

\section{Désinfection du matériel végétal}

Nous choisissons soit des feuilles présentant déjà des symptômes d'oïdium visibles à l'œil nu (technique A), soit des feuilles contaminées artificiellement, maintenues 3 jours en chambre humide et ne présentant pas encore de symptômes (technique B), soit des feuilles saines (technique $\mathrm{C}$ ) provenant de plantes élevées dans des enceintes spéciales (FAUVEL \& MOLOT, 1985).

Ces feuilles sont prélevées avec un pétiole suffisamment long, immergées pendant $3 \mathrm{mn}$ dans du 

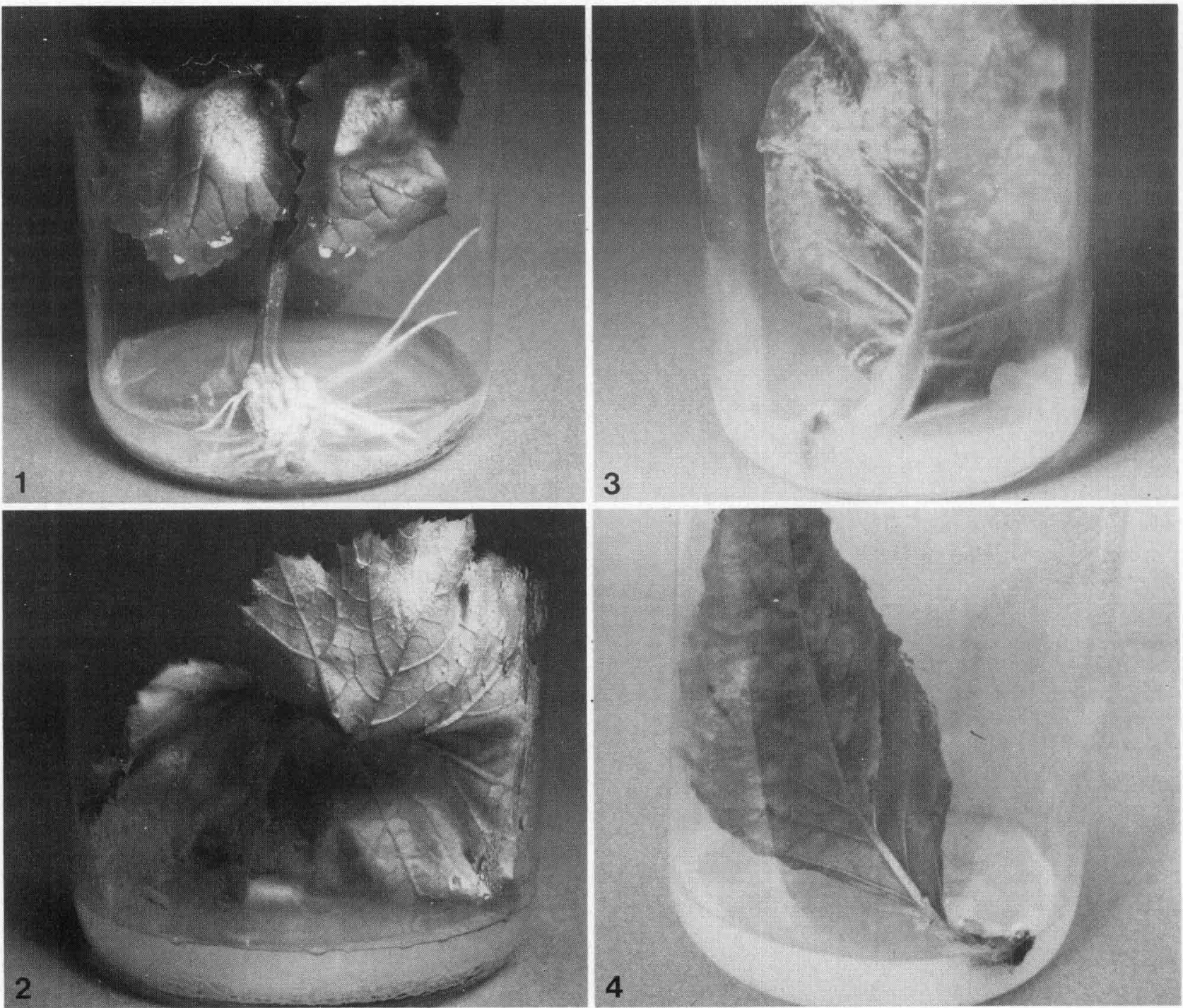

$\mathrm{HgCl}_{2}$ à 0,5 p. 1000 et rincées une fois à l'eau stérile. Après un rapide séchage sur papier buvard stérile, elles sont introduites dans des bocaux renfermant le milieu nutritif gélosé ; leur pétiole est enfoncé dans la gélose ; le limbe demeure au-dessus du milieu, sa face supérieure étant tournée vers le haut, sauf dans le cas du piment (la contamination artificielle par $L$. taurica s'effectuant mieux sur la face inférieure).

\section{Désinfection des spores d'oüdium}

Sur le matériel végétal sain et désinfecté superficiellement, il convient d'apporter des spores d'oïdium ayant elles-mêmes subi une désinfection.

La récolte des spores s'effectue par agitation de feuilles infectées dans l'eau selon une technique déjà décrite (MOLOT \& LECOQ, 1986). La suspension de spores obtenues est mélangée volume à volume à du $\mathrm{HgCl}_{2}$ à 1 p. 1000 . Le temps de désinfection ne doit pas dépasser $2 \mathrm{mn}$. Les spores retenues sur un filtre Seitz (référence K5) sont reprises 2 fois par de l'eau stérile et pulvérisées à la surface des feuilles déjà introduites dans les bocaux ; cette opération est réalisée sous hotte à flux laminaire à l'aide d'un vaporisateur à chromatographie chargé avec du fréon 12 .

Le matériel contaminé exclusivement par l'oïdium est installé d'abord à $22{ }^{\circ} \mathrm{C}$ sous 8000 lux jusqu'à

Photo 1

Sphaerotheca fuliginea sur la face supérieure d'une feuille adulte de courgette. Au contact du milieu nutritif gélosé, il y a formation de nombreuses racines.

Sphaerotheca fuliginea (powdery mildew) on the upper side of an adult squash leaf. Note formation of numerous roots in the nutrient agar medium.

Photo 2

Sphaerotheca fuliginea sur la face inférieure d'une feuille adulte de courgette. La tache blanche (en bas et au centre) correspond à une zone de jeunes racines en formation.

Sphaerotheca fuliginea (powdery mildew) on the lower side of an adult squash leaf. The white spot (at base and center) shows young roots in formation.

Photo 3

Erysiphe cichoracearum sur feuille de tabac.

Erysiphe cichoracearum (powdery mildew) on tobacco leaf.

Photo 4

Leveillula taurica sur feuille de piment. On remarque, à l'extrémité du pétiole, la formation d'un cal.

Leveillula taurica (powdery mildew) on pepper leaf. Note callus at end of the petiole.

Clichés I.N.R.A. (J. ROUGIER). 
apparition des premières taches de la maladie, puis à $16^{\circ} \mathrm{C}$ sous 2000 lux. Dans les 2 cas, la durée d'éclairement est de 12 heures par jour.

Pour un essai donné, chacune des 4 plantes utilisées compte au total 5 bocaux ; tous les essais ont été répétés au moins 2 fois.

\section{RÉSULTATS}

\section{A. Mise en culture de feuilles présentant des symp- tômes d'oïdium lors du prélèvement (technique $A$, tabl. 1)}

Le choix d'un tel matériel ne semble pas convenir pour $E$. cichoracearum et $S$. fuliginea. Après désinfection, les colonies de ces 2 oídiums ont un aspect " effondré " résultant sans doute de la désintégration des chaînes de conidies et il n'y a pas (ou pratiquement pas) de nouvelle sporogenèse. En revanche, le taux de réussite est excellent avec $L$. taurica, l'oïdium interne du piment.

L'utilisation de matériel malade n'est pas favorable à la formation de cals et surtout de racines, vraisemblablement en raison du métabolisme du végétal ralenti par le parasitisme; les conditions de survie sont en général réduites à 3-4 semaines, ce qui limite beaucoup l'intérêt de la technique.

\section{B. Mise en culture de feuilles contaminées artificielle- ment 3 jours avant d'être désinfectées (techni- que B, tabl. 1)}

Cette technique donne de bons résultats avec les 3 oïdiums expérimentés. La sporogenèse se manifeste au bout de 7 à 10 jours pour $S$. fuliginea ou E. cichoracearum, au bout de 20 à 22 jours pour L. taurica. En raison de la formation de cals et de racines le long du pétiole en contact avec le milieu gélosé, la survie du matériel peut atteindre et dépasser 2 mois.

\section{Mise en culture de feuilles saines suivie d'une contamination artificielle (technique $\mathrm{C}$, tabl. 1)}

Cette $3^{\text {e }}$ façon de procéder donne entière satisfaction. Les feuilles adultes des différentes plantes-hôtes forment toutes des cals ; il y a émission de racines, en grand nombre chez la courgette et le concombre, en quantité beaucoup plus réduite chez le tabac ; seul le piment se refuse à former un système radiculaire ; mais, dans tous les cas, une feuille adulte peut, en l'absence d'oïdium, se maintenir en vie pendant 3 à 4 mois. Signalons cependant que le melon et la pastèque se prêtent assez mal à cette technique.

Après pulvérisation des spores, les feuilles de courgette et de concombre se recouvrent de colonies d'oïdium (aussi bien $S$. fuliginea que $E$. cichoracearum) de façon régulière et abondante en 1 semaine environ ; chez le tabac, les symptômes apparaissent de manière plus sporadique au bout de 8 à 10 jours et chez le piment au bout de 20 à 22 jours.

Le taux de pollution demeure très faible. Malheureusement, sous l'influence du parasite (et surtout si la contamination est importante) les tissus se nécrosent au bout de 2 mois. Il convient alors de transférer l'oïdium, à l'aide d'un petit pinceau stérile, sur une feuille saine convenablement désinfectée ; cette opération ne pose aucune difficulté.

Après plusieurs cultures successives, nous n'avons jamais constaté de pertes d'agressivité du champignon.

\section{DISCUSSION. CONCLUSION}

La technique que nous venons de décrire et qui a permis la mise en culture de quelques oïdiums a nécessité d'une part la préparation d'un milieu spécial sus-

TABLEAU

Formation de cals et de racines et apparition de symptômes d'oïdium sur feuilles adultes de différents hôtes maintenues en survie, en conditions axeniques, sur milieu nutritif gélosé (en fonction de l'importance du phénomène : $-, \epsilon,+,++$ ).

Callus and root formation, and powdery mildew symptoms, on adult leaves of squash, cucumber, pepper and tobacco: detached leaves cultured on agar medium, in axenic conditions (according to the intensity : $-, \epsilon,+,++$ ).

\begin{tabular}{|c|c|c|c|c|c|c|c|c|c|c|c|c|c|c|c|}
\hline \multirow[b]{3}{*}{ Courgette } & \multicolumn{5}{|c|}{ Technique A } & \multicolumn{5}{|c|}{ Technique B } & \multicolumn{5}{|c|}{ Technique $\mathrm{C}$} \\
\hline & Cals & Racines & S.F. & E.C. & I..T. & Cals & Racines & S.F. & E.C. & L.T. & Cals & Racines & S.F. & E.C. & L.T \\
\hline & $\epsilon$ & $\epsilon$ & $\epsilon$ & $\epsilon$ & & + & $+t$ & + & + & & + & $+t+$ & +++ & ++ & \\
\hline Concombre & $\epsilon$ & $\epsilon$ & $\epsilon$ & $\epsilon$ & & + & + & + & + & & + & ++ & +++ & +++ & \\
\hline Piment & + & - & & & ++ & + & - & & & + & + & - & & & + \\
\hline Tabac & $\epsilon$ & - & & $\epsilon$ & & + & $\epsilon$ & & + & & + & $\epsilon$ & & + & \\
\hline
\end{tabular}

Technique A. Feuilles présentant des symptômes d'oïdium lors du prélèvement.

Technique B. Feuilles prélevées saines et contaminées artificiellement 3 jours avant la mise en culture.

Technique $C$. Feuilles prélevées saines et contaminées artificiellement le jour de la mise en culture.

Technique A. Leaves with powdery mildew at the time of sampling.

Technique B. Healthy leaves artificially infected 3 days before pricking in agar medium.

Technique $C$. Healthy leaves infected at the time of pricking in agar medium.

S.F. = Sphaerotheca fuliginea .

E.C. = Erysiphe cichoracearum (souche Cucurbitacées ou tabac).

L.T. = Leveillula taurica. 
ceptible de favoriser l'enracinement de la feuille adulte, d'autre part la désinfection du matériel végétal et des spores selon un procédé original. Ne provoquant aucune décoloration du limbe (contrairement à ce qui se passe avec l'hypochlorite de calcium ou de sodium), le bichlorure de mercure, utilisé pendant diverses durées de trempage, s'est révélé un désinfectant de choix. A notre connaissance, les auteurs qui ont cherché à réaliser des cultures associées de tissus végétaux et de parasites obligatoires ne désinfectaient pas les spores ; dans le cas d'Uncinula necator par exemple, on était obligé de faire un très grand nombre d'inoculations pour en obtenir qui ne soient pas contaminées (MOREL, 1948). Par notre méthode, le taux de pollution est très faible. De plus la formation de cals et de racines, notamment chez la courgette et le concombre, permet d'augmenter de façon notable la durée de vie de la feuille ( 3 à 4 mois si elle est saine, 2 mois si elle est contaminée).

La méthode que nous avons mise au point devrait assurer, dans d'excellentes conditions d'isolement, la conservation de différentes races physiologiques de $S$. fuliginea, permettant ainsi d'entreprendre un travail de sélection valable. Il importe toutefois de ne mettre en culture que des organes foliaires adultes, car des limbes prélevés à un stade trop jeune ou trop âgé manifestent une certaine résistance vis-à-vis de l'oïdium (FERRIERE \& MOLOT, 1987).

Relativement aisée lorsqu'elle est réalisée en bocaux d'assez grand volume, la culture associée de l'oïdium et de la feuille devient plus difficile en boîte de Petri, sans doute en raison d'un taux d'humidité trop élevé : les résultats sont positifs avec $S$. fuliginea, négatifs avec $E$. cichoracearum. La mise au point d'une technique de conservation miniaturisée présenterait pourtant des avantages ; aussi, grâce aux résultats déjà acquis, nous envisageons de cultiver les oïdiums sur couche épidermique monocellulaire de cotylédons de Cucurbitacées. Des essais ont déjà été réalisés dans cette voie sur lambeaux de coléoptile, notamment avec les couples orge- $E$. graminis $\mathrm{f}$. sp. hordei (BUSHNELL et al., 1977) et avoine-Puccinia coronata (MENDGEN \& DRESSLER, 1983).

En vue d'améliorer encore les performances de notre technique, nous envisageons d'associer au développement radiculaire une culture d'endomycorhizes qui, en favorisant l'assimilation des éléments nutritifs, devrait assurer aux feuilles une durée de vie plus longue.

Recu le 15 décembre 1986. Accepté le 15 février 1987.

\section{RÉFÉRENCES BIBLIOGRAPHIQUES}

Boasson R., Shaw M., 1982. A stimulus for sporulation of axenically grown flax rust. Exp. Mycol., 6, 1-6.

Bose A., Shaw M., 1974. Growth of rust fungi of wheat and flax on chemically defined media. Nature, 251, 646-648.

Bushnell W. R., Dueck J., Rowell J. B., 1977. Living haustoria and hyphac of Erysiphe graminis $\mathrm{f}$. $\mathrm{sp}$. hordei with intact and partly dissected host cells of Hordeum valgare. Can. J. Bot., 45, 1719-1732.

Dahmen H., Staub Th., Schwinn F. J., 1983. Technique for longterm preservation of phytopathogenic fungi in liquid nitrogen. Phytopathology, 73, 2, 241-246.

Doling D. A., 1966. The use of benzimidazole for detached leaf cultures of Puccinia striiformis. Cereal rust conferences, Cambridge, 1964.

Fauvel C., Molot P. M., 1985. Une enceinte de conception fort simple pour l'étude des oüdiums. Cah. Techn. I.N.R.A., 11, 9-20.

Ferriere Halina, Molot P. M., 1987. Sensibilité des Cucurbitacées à Sphaerotheca fuliginea en fonction de l'étage foliaire. Phytopathol. Z. (sous presse).

Grambow H. J., Riedel S., 1977. The effect of morphogenically active factors from host and nonhost plants on the in vitro differentiation of infection structures of Puccinia graminis f. sp. tritici. Physiol. Plant Pathol., 11, 213-224.

Hotson H. H., Cutter V. M., 1951. The isolation and culture of Gymnosporangium juniperi-virginianae Schw. upon artificial media. Proc. Nat. Acad. Sc. USA, 37, 400-403.

Konidaris J., 1985. Conservation des champignons phytopathogènes dans l'azote liquide, après congélation progressive obtenue avec le Minicool. Mémoire de fin d'études ENSA Montpellier. DAA Protection des cultures, $58 \mathrm{p}$.

Kuck K. H., 1979. Über die infektionsbedingten Veränderungen der Aminosäuren und Fettsäuren in mit Puccinia graminis $f$. sp. tritici Rasse 32 infizierten Weizenblättern und die in vitro-Sporulation des Pilzes. Dissertation, R.W.T.H., Aachen.

Kuck K. H., Reisener H. J., 1985. In vitro sporulation of race 32 of Puccinia graminis Pers. f. sp. tritici Erikss. et Henn. Physiol. Plant Pathol., 27, 259-268.
Maclean D. J., 1982. Axenic culture and metabolism of rust fungi. In Scott K. H. \& Chakravorty A. K. : «The rust fungi», 37-120. Acad. Press, London and New York.

Mendgen K., Dressler Elvira, 1983. Culturing Puccinia coronata on a cell monolayer of Avena sativa coleoptile. Phytopathol. $Z ., 108$, 226-234.

Molot P. M., Lecoq H., 1986. Les oidiums des Cucurbitacées. 1. Données bibliographiques. Travaux préliminaires. Agronomie, $6(4), 355-362$.

Morel G., 1948. Recherche sur la culture associée des parasites obligatoires et des tissus végétaux. Ann. Epiphyties, 14, 123-234.

Rapilly F., 1968. Les techniques de mycologie en pathologie végétale. Ann. Epiphyties, 19, H.S. 102 p.

Samborski D. J., Forsyth F. R., Person C., 1958. Metabolic changes in detached wheat leaves floated on benzimidazole and the effect of these changes on rust reactions. Can. J. Bot., 36, 591-601.

Turel F. L., Ledinghan G. A., 1957. Production of aerial mycelium and uredospores by Melampsora lini (Pers.) Lev. on flax leaves in tissue culture. Can. J. Microbiol., 3, 813-819.

Vallos Christine, 1984. Multiplication in vitro du piment (Capsicum annuum $L$ ). Etude du microbouturage et de l'embryogenèse somatique. DEA Sciences agronomiques. Option Phytotechnie. Montpellier, $45 \mathrm{p}$.

Williams P. G., 1984. Obligate parasitism and axenic culturc. In Bushnell W. R. B. \& Roelfs A. P. : «The cereal rusts». Acad. Press, New York.

Williams P. G., Scott K. J., Kuhl J. M., 1966. Vegetative growth of Puccinia graminis f. sp. Iritici in vitro. Phytopathology, 56, 1418-1419.

Williams P. G., scott K. J., Kuhl J. L., Maclean D. J., 1967. Sporulation and pathogenicity of Puccinia graminis f. sp. tritici grown on an artificial medium. Phytopathology, 57, 326-327.

Wolfe M. S., Macer R. C. F., I966. The use of kinetin in the detached leaf cultures of Puccinia striiformis. Cereal rust conferences, Cambridge, 1964. 